\title{
9 The gender professional as ethnographer
}

\author{
Working for equitable forests
}

\author{
By Rebecca Elmhirst and Bernadette P. Resurrección \\ In conversation with Carol J. Pierce Colfer
}

\section{Introduction}

Ethnography is a research approach integral to the discipline of anthropology, which typically relies on the researcher's immersion in social settings through a sustained engagement with people's complex, everyday lives. Feminist ethnography pays particular attention to power and culture as played out in 'the field', and how lived experience is gendered, classed, racialised and sexualised. This approach typically disrupts other kinds of knowledges that seek to reduce human behaviour to economic rationalities, and instead emphasises meaning-making through close (participant) observation and other qualitative methods based on conversation. The relationship between development practice and anthropology (including its constituent method of ethnography) is complex and has inspired an extensive literature that has explored the way in which the field itself emerged from development's colonialist origins (i.e. its role in seeking to understand diverse peoples in order to govern them) and more recently, considers the role of ethnographic knowledge as 'evidence' in development settings (Lamphere, 2004; Crewe \& Axelby, 2013; Gardner and Lewis 2015; Eversole, 2018). Ethnographic approaches are found in the tools, techniques and framings of environment and development practice, ranging from the participatory rural appraisal tools influenced by ethnographic fieldwork methods (Chambers, 1994) to a focus on the social dynamics of institutions, an example being the mobilisation of the concept of 'social capital' within the World Bank's programming in Indonesia in the 2000s (Bebbington et al., 2004; Li, 2011).

The 'equitable forest' referred to in the title of this chapter relates to the work of Carol Colfer, an anthropologist by training, who has spent nearly 25 years in forest-related research with the Center for International Forest Research (CIFOR), an international non-profit interdisciplinary research organisation headquartered in Bogor, Indonesia. As one of the Consultative Group on International Agricultural Research centers (CGIAR), CIFOR's core business is to improve forest management in the tropics in such a way that it is good for people and the environment through better policy, practice and human capacity. Carol's work with CIFOR 
has focused on equity and well-being of people in forest contexts, and this has involved field research, the development of appropriate participatory tools and methods, and training for stakeholder engagement. She has worked in various development sectors, ranging from forestry to agriculture to health, and whilst gender featured in much of this work, it has been over the past five years that she has been contracted specifically as a gender professional by CIFOR, bringing together her ethnographic and gender expertise. Much of Carol's work at CIFOR (and with earlier agricultural projects) has coincided with the 'ethnographic turn' $(\mathrm{Li}, 2011)$ that was taking place in other leading development organisations in the 1990s and early 2000s, most notably the World Bank but also USAID, where anthropologists were being hired to advance a wider agenda of community-based participatory research, including within the natural resource management sector.

In technical research environments, such as forest research institutes, ethnographers have to wear their 'boots-on-the ground' and engage with local communities, whilst at the same time collaborating with professional teams from a range of disciplinary backgrounds. The emphasis on people and institutions in community-based environment and development work means importance is bestowed on field-based social research as part of concerted efforts to discover the best means to enable people and their institutions to sustainably manage natural resources. For the gender professional working in such contexts, there is a need for engagement with diverse groups of people, from forest communities and local government, through to scientists from across a range of disciplines. Where does 'gender' fit within this process of navigating across and between different cultures (in many senses) and epistemologies in forestry research and practice? In this chapter, Carol discusses her experiences of being an ethnographer and a gender expert within a natural resources management context: both being professional identities which are drawn upon to bridge different types of knowledge and cultures to arrive at common understandings that will later guide action or enable solutions. An 'ethnographic sensibility' is key to this bridging challenge, and in weaving between the knowledges and approaches that underpin professional and academic anthropology, gender analysis and multi-stakeholder analysis in natural resource management settings.

\section{Becoming a gender specialist and applying anthropological approaches}

Carol spent her childhood in Turkey from the age of nine to 16, a formative period of her life. Her mother, like her father, was attending graduate school; her father was very supportive of women being educated and having a career, which set her family apart from most others. These years in another country, and the subsequent surprise of personal experience of gender discrimination, sensitised her to differences in ways gender plays out. In the early 1970s, she was very involved in the women's movement, which strengthened her commitment to pursue her doctoral work on gender issues. She was hired early on as a 'gender professional' being a Women in Development specialist in 1979-1981, and later 
a farming systems specialist, an anthropologist, a senior scientist, a community development specialist, a leader of adaptive collaborative management (ACM), and more. Throughout this portfolio of appointments, all served in interdisciplinary contexts, her own purpose and often her remit as well, was to integrate gender. However, as she remarks: 'Not being called a gender specialist probably helped me to be heard by others', briefly hinting at the unhelpful connotations tied to being labelled as one. We asked Carol about her positioning as a 'gender professional'.

Babette: How do you represent yourself to people?

Carol: I was trying to gender mainstream for so many years. It was very easy for me to assess the audience that I was talking to. So, my automatic gut answer if somebody says, 'What are you?' I'd say, 'an anthropologist'. But whether I emphasised the gender part or not, depended very much on the context. If I was talking to Norwegian donors, then I would emphasise gender. If I was talking to a team of forest officers in Zimbabwe, I would emphasise the interest in working collaboratively with local people, and I might stick in there the need to work with women, just to give a little hint that I wasn't only going to be talking to the men. And otherwise, and over time, you become more and more upfront about that in those somewhat partially hostile or potentially hostile contexts.

Carol explains that her background in anthropology has provided more than a set of tools for people-centred forestry work. As a discipline, anthropology enables a holistic perspective for dealing with complex issues. But for the applied anthropologist working in an interdisciplinary setting, there is also a requirement to translate and bridge.

Carol: I am an anthropologist and feel that this discipline has been an excellent grounding for gender studies. But it has also been valuable to work collaboratively with other disciplines, to learn what elements of gender studies 'speak' to practitioners [from other disciplines such as biophysical sciences and economics, for example]. Development-related issues are complex and holistic, and that's what anthropologists investigate. It has been extremely important for understanding the world and finding possibilities for empowerment. This grounding is also important for communicating with other disciplines, although this is one that requires much work as you have to convert the complexities [of social life] into something that fits better with the more linear approach that conventional positivist scientists often prefer. Many of the biophysical scientists I worked with liked to look for the [one] cause of phenomena, rather than trying to understand the complex interconnections among parts, including feedbacks and circular and mutual causation. They wanted to simplify to test for one result or another in search of general principles, whereas my own interest was in figuring out the workings of a particular 'whole' that might (or might not) represent a broader category. 


\section{Mobilising ethnographic practice to bridge disciplines}

Given the debates that have emerged around applied anthropology in development settings, and the challenges other authors have noted with regard to the knowledge hierarchies that can challenge the integration of ethnographic approaches in interdisciplinary contexts dominated by positivist natural and social sciences, we were interested in learning how Carol navigated potential knowledge politics at CIFOR, particularly with regard to work on gender.

Babette: What were the different disciplines at CIFOR? Were there compelling breakthroughs you've experienced in bridging your professional gender knowledge with the technical knowledge of your colleagues?

Carol: CIFOR has an interdisciplinary staff which plans and coordinates research on forest- and people-related topics, with partners in developing countries. There are typically foresters, ecologists, biologists, geographers, anthropologists, sociologists, economists, hydrology specialists, quite a range of disciplines. The mandate of the scientists is to do comparative research mainly that examines the relationships among people, environment and, to a lesser extent, production. Partnership and interdisciplinary collaboration have been keystones of the institution.

The institutional context of CIFOR has favoured an interdisciplinary approach, and much emphasis has been on forest governance and natural resource management through multi-stakeholder work that necessarily requires expertise beyond positivist science. But Carol also notes that a key factor that has facilitated the integration of gender concerns into CIFOR's work has come through a cornerstone of ethnographic practice, that is, fieldwork.

Carol: Going to the field with other people is so, so valuable for making gender differences obvious. Working together in the field is hugely powerful in getting others from a variety of fields to realise that gender is important, but it's not always easy to arrange shared fieldwork (of some duration). It's also useful to see the clever things that women come up with when you give them a chance, as we were able to do in some of the adaptive collaborative management (ACM) projects and CAPRi (Collective Action and Property Rights) work (Colfer, 2005a; Komarudin et al., 2011). This changes researchers' perceptions of women as being too busy or too dumb or too disempowered to act.

An ethnographic sensibility is also put to work in bridging knowledges of colleagues in a very practical sense, and this is another factor that Carol suggests enables a better uptake of gender knowledge in interdisciplinary environment and development work.

Carol: I think we need to tailor our analyses very carefully to the various audiences. We have to meet them where they are: which of course means that we 
have to double our work, because the transformative work requires sophisticated social scientific analyses whereas the communication with unconvinced folks requires simplification, among other things. I'd say we also need to avoid giving any impression of disdain for the ignorance of our non-social science colleagues (after all, we are as ignorant of their fields). We need to cultivate real respect for others' knowledges, whether villagers or colleagues in research centres or academia. Colleagues tend to be defensive and to fall back on the superior prestige of the 'hard sciences' (which hardens their commitment to positivist approaches) when we behave disrespectfully.

While working in interdisciplinary contexts and doing my gender work, I applied an ethnographic approach to other disciplines. I tried to understand their world view, their scientific traditions and assumptions, their customs. And I think that's been very helpful since I'm able to stand back and think, 'Okay, let's look at their worldview as an agronomist, or as an ecologist, or whatever, from a kind of ethnographic perspective'. I found that it was really helpful working with them more smoothly.

Becky: That's really interesting. So actually, you were using your skill as an anthropologist to enter their lifeworld and language.

Carol: Yes, I came to understand how they look at whatever we're doing together. It helps me. I mean, it's not that we have any kind of big disagreement. I see that it's simply different ways of looking at things. And if I can understand how they're looking at the research situation, then I can rephrase things a bit. This also allows easier interdisciplinary collaboration, I think.

Part of the job of the ethnographic researcher is typically to explore the details of everyday life which otherwise go unnoticed, trying to read the silent scripts that organise ordinary activities (Dove \& Kammen, 2015). Ethnographers appreciate the extraordinary-in-the-ordinary that may help to understand the ambiguities and obscurities of social life (Ybema et al., 2009). By doing fieldwork, ethnographers examine the complexities of local contexts and their influence on development outcomes, such as say, in the sustainable forest management project that CIFOR as an organisation aspires to. 'The field' is not only where one observes changing structures and dynamics of local people, but as Carol says, it is also somewhere one can work collaboratively with other disciplines, to learn what elements of gender studies 'speak' to them. It does seem that immersion in field contexts with interdisciplinary teams allows the ethnographer to understand how colleagues, for their part, make sense of their surroundings with the possibility of learning about the social processes that situate their knowledges. This enables her to translate complex social realities into understandable languages and devices that will create common understanding and cultivate in them an appreciation of the social dimensions of things.

\section{Creating common understandings: numbers and generalisations}

A perennial challenge for anthropologists working in interdisciplinary development contexts is to develop knowledge that 'works' within the logics of dominant 
networks within the organisation and/or project in which they are based (Forsyth, 2011): a challenge that is also faced in gender research (Kunz \&Prügl, 2019). The use of numbers within participatory research and rapid rural ethnography methods and tools is a well-recognised strategy for bridging across epistemologies through a common research language. Our discussion turned to this issue and the role numbers had played in creating common understandings within Carol's work at CIFOR.

Becky: Could you tell us more how the interdisciplinary collaboration worked out?

Carol: The thing that came to mind immediately was the Who Counts framework that I developed. It's a matrix. It has seven dimensions, and these are dimensions that I developed when I was realising what my forester friends were not noticing, when we were in the field together. The goal of that particular project was to develop criteria and indicators for sustainable forest management. That was the name of the project. And my component of it was on human well-being. Well, none of us really had any idea of how to start looking at that in a forestry context. We were working with very, very marginalised peoples in West Africa. I came up with some things that I thought were really central to involving marginalised people in forest management, and I fashioned those into seven dimensions. I was also aware my companions were completely numbers-oriented. Anything that you could possibly convert into a number would be much more acceptable to them, believable by them. And so, I made this matrix which had the stakeholders across the top, such as the original inhabitants, the migrants in the villages and the forest service, which differed in every place. We listed six or seven across the top, and then we had these seven dimensions down the side, and then we went to various people who knew about the area and we asked them to give a score for each dimension, for example, the severity of poverty. It's nothing precise, but it does kind of give you an idea of the differences among the different stakeholders on these dimensions that are important for human well-being. I'm not a very quantitative person, but I had to think of ways to do simple quantification because it really helps in communicating with non-social scientists. I've become a great believer in triangulation that includes some simple quantitative elements.

The resulting tools were published by CIFOR as a series of guides, similar to the rapid and participatory rural appraisal tools that have been associated with the integration of ethnographic approaches within natural resource management research (Colfer et al., 1999a; 1999b; 1999c). They continue to be used: Carol notes that she has recently used some of the tools in research in forest communities in the western United States.

Babette: What are your starting points in integrating gender with forest resource management? Do you consider impacts of deforestation? Do you look at the 
paucity of gender-disaggregated data? Do you look at the experiences of women (and men)?

Carol: I have always been concerned with all of those things. My ideal starting point is to work collaboratively with women and men, so we can get a feeling for the holistic context and integrate intersectionality issues. I like to develop collaborative goals and related plans based on what local people want and figure out ways to marry that with wider-ranging goals and concerns from the outside. I think this is the only way we'll get any kind of sustainable solutions (to the changing and variable conditions we encounter in the field). That was possible with the ACM (adaptive collaborative management) project, which I led, but has not been with many of CIFOR's projects (Colfer, 2005b).

Aside from developing tools that involve some simple quantification in order to bridge and triangulate with other knowledge frameworks, we discussed a second issue that is commonly raised in relation to ethnographic work in development contexts, and that is the pressure to scale up and generalise beyond the local context. Here, the principal line of tension is between quantitative (which emphasise the extent of phenomena) and qualitative (the meaning of phenomena) approaches to knowledge.

Babette: Were your technical colleagues concerned about knowledge being biased and the numbers having to be very big for them to actually mean anything?

Carol: The jobs that I've had at CIFOR have all been community-based - either community-based or small area-based. Given that we were working in smallscale contexts, dealing with big numbers has not really been such an issue. We talked a lot at CIFOR about different scales, and it was acceptable to the institution for me to focus on the local level, which provided a framework for the numbers we could come up with. But if I'd been purely qualitative, it would have been kind of alien and they would have worried more about how to assess it.

Babette: As much of your work was actually community-based, was there any concern from within CIFOR or any other organisation you were affiliated with to actually try to find out what can be generalisable from the community-based studies you've done?

Carol: When we first started the project called adaptive collaborative management, I had that problem again and again, both from the administrators within CIFOR and also from the Board of Trustees. And I argued that if we're trying to manage forests, they are in a particular place - something CIFOR scientists readily recognised. Every forest is different, every community is different. We really are going to have to come up with some techniques of finding out about peoples' lives that are transferable. We can't transfer the information specifically about that place. We have to transfer the ability to find out such information about each individual place. And I really believe that.

In other words, what has been scalable are the tools themselves, rather than the knowledge produced by the tools. 


\section{Pragmatics of positionality and participation in ethnographic action research on gender}

Work on feminist epistemology and research places fundamental importance on how research is conducted (regardless of singular or multiple methods) and to what purpose (Harding, 1987). Reinharz (1992) characterises feminist research as being (i) focused upon analysing and understanding gender within the context of lived experiences; (ii) committed to social change, and (iii) committed to challenging thinking about the researcher's subjectivity and the relationship between the researcher and the researched. The commitment to change and attention to the relationships with research subjects are key to feminist research. Practices of reflexivity - researchers reflecting on their positionality, critically examining the research process, and the commitment to change (Hesse-Biber, 2014), and attention to the relationships between the researcher and the research subjects (Stacey, 1988; Nagar, 2003; Craven \& Davis, 2013) - stand out as the defining characteristics of feminist research.

Diane Wolf (1996) additionally draws attention to the uneasy situations in the research process, which she argues, centrally revolve around power: power differences stemming from different positionalities of the researcher and the researched (race, class, nationality, life cycle and age, urban-rural backgrounds); and power exerted during the research process, such as defining the research relationship, unequal exchange, and exploitation. Underlying all these is the feminist imperative to transform and create positive change, which undoubtedly has its share of uneasy arrangements and troublesome outcomes. How have these kinds of issues arisen in Carol's work? Given the pragmatics of applying anthropology in an environment and development context, what kinds of compromises and reversals have been encountered that complicate the 'agency' of the researcher to follow a participatory and transformative agenda that is aspired to in academic discussions, for example?

Babette: How do you see questions of your own positionality affecting your role, practice, authority and voice as a gender professional?

Carol: At the moment, I'm an elderly white-haired woman with lots of experience, so that makes things easier, I'd say (though admittedly I've changed my role to one of basically consulting, rather than being central in the organisation, as I was when I was more energetic and directly involved in all the politics). Being white, speaking English, being American - all have made my life easier, giving me automatic power in contexts where I could have been marginalised (and would have been when I was younger, and also when the world social context was less attuned to gender issues). My own positionality also affects my feelings about gender, the social arrangements I find pleasant, agreeable, desirable (which may not be what those I work with seek). This has sometimes been a dilemma for me. In the Middle East, for instance (before my CIFOR work), I felt some horror at the idea that women needed taking care of; yet Omani women and other Middle Eastern women I met had 
grown up seeing that as something positive, seeking a man who 'would take care' of them. I think I was able to damp down my dismay, but I always have struggled with trying to do what was right, juggling what I personally desired, with what those I was working with desired for themselves.

Saying all this, I was thinking about my role in CIFOR and the potential for me to be marginalised. But there's another element, which is my role in interaction with villagers. Although I was always aware of power dynamics, the degree to which my own position gave me power was not as clear to me as it became when we moved from village level work to work at the district level. In the latter context, it quickly became clear that district officials in Indonesia and elsewhere, had considerably more power in our relationships than had the villagers I'd dealt with (Colfer, 1983). The officials could refuse to collaborate, contradict or disagree with conclusions we put forth, move key players into other roles; withdraw funding; etc.

Becky: Some of the hesitancy, even resistance to doing work on gender with a transformative agenda, is that we're intervening in other people's cultures. And you've said that they do need fixing in a way. But I wonder if you've got any examples about field contexts where you faced that sort of tension in a very real sense and were caught between doing something and inaction. Was there anything where you stepped back a little bit from something because you felt uncomfortable around some of the transformations that your intervention could then lead to?

Babette: Yes, in fact, disrupting cultures is always made as a popular excuse not to meddle with gender inequalities.

Carol: Yes, people say, 'Why are you doing gender? You're trying to change cultures.' But what about the big logging or plantation industries who come into a community's traditional territory, take over or adversely affect their means of livelihood, influence local level politics? They are also changing gender (see Elmhurst et al., 2016) So, I guess it's just a matter of perspective. I do have a few examples to share where there were some tensions that had to do with disrupting the way things were being done.

The examples Carol outlines below from various projects she worked in also reveal the limits of researcher agency in working collaboratively at community and local government level in contexts where strong gender norms restrict what is achievable in the research.

Carol: In Zimbabwe, as part of CIFOR's ACM program, we were working with women to make their use of local grasses more sustainable - a goal they had identified themselves (Standa-Gunda et al., 2003; Vanclay et al., 2006). They'd developed a new way of making brooms that involved more sustainable use of the grass, as well as being more attractive. They wanted to bring their brooms to a trade fair the government was organising in another town, as a way of disseminating the new technique and also to sell the brooms they'd made. The idea was concocted jointly by the women, our fieldworkers, 
and government officials. The husbands, fearing danger and infidelity, did not want the women to go to the fair. In discussions it became clear that there would be no problem if the women went in a group, so the trip was planned that way (Mutimukuru-Maravanyika et al., 2008).

Recognising that women were also actively involved in fishing in Danau Sentarum Wildlife Reserve (now National Park) in West Kalimantan, we planned to bring together fishers from each community in the reserve to discuss ways to manage the fishery in a better way (Colfer et al., 1996). We asked that each community send three people, with at least one woman. Very few communities sent their woman representative. We conducted the meeting anyway. At least the idea had been floated.

In the same community, I arranged to accompany a woman to her rice field, which was behind her village. I wanted to be alone with her because I was new in the community and my Melayu language skills were minimal. I found it easier to understand one person at a time; and I also wanted to get the woman's views. My assistant was a man. He and she both agreed to this plan, and I went off alone with her. We were having an excellent time; she was getting progressively more comfortable and willing to talk, when he decided to come and join us - with a whole band of villagers! I did not handle the situation well, stomping off in irritation. He said he'd come to help me with the language; but he may also have come because the community may have been fearful that I'd hurt her. There was a long history of conflict between the neighbouring Iban and these Melayu, with the Iban particularly feared as (ex)headhunters - though there had not been any direct conflict for decades. There remained significant fear of strangers though, with rumours of maltreatment rife. At one point, for instance, there were concerns that we planned to sacrifice a local virgin and plant her under the support beams of the Danau Sentarum Field Center. The woman I was interviewing was genuinely frightened after I stomped off, never to speak with me again. This was not my most stellar fieldwork moment.

Carol's accounts above demonstrate to us that efforts towards being inclusive in field contexts - or the 'feminist will to improve' - are fraught with tensions, usually prompting us to resort to compromises and pragmatic responses that fall short of our original well-intentioned goals. In situations where local patriarchal norms are particularly strong, feminist research interventions often prove to be challenging. We are also reminded of the need to bridge the gap between research agendas and change that's needed on the ground, as it is increasingly becoming clear that even as social research seeks to analyse and address persistent inequalities, marginalisation and disadvantage, new layers of inequality keep emerging, ever more subtle and difficult to deal with. Carol notes that certain structural inequities related to capitalism, or normative ones related to religions are particularly intransigent.

Feminist scholar-activist researchers have stressed the importance of developing research questions and analytical frameworks with communities so that 
research findings do not become inaccessible and meaningless to the people whose lives the research is intended to improve (Nagar, 2003), an approach that echoes early iterations of participatory research, sometimes dubbed 'rapid rural ethnography' (Chambers, 1994. Both the ACM and CAPRi programs that Carol led were structured specifically to address this issue. Great efforts were made to ensure that the issues addressed, the solutions offered, the ways of monitoring progress, and assessment of results - iterations built into the approach - came from the local people. However, in development research, where Carol and Babette focus their efforts, research agendas are often pre-arranged, guided in large part by the normative goals of the donors and development paradigms in currency. This is illustrated in what Carol describes as a less successful attempt with adaptive collaborative management, when the leader of the broader team was not sufficiently convinced of the need for local level decision-making. He was tethered to the wishes of his donor, which meant the approach simply did not work (Colfer et al., 2011). It is often envisaged that the role of (gender and) development research is 'to inform appropriate and sustainable development policies and practice'. Without a solid understanding of the local context and local needs as well as of broader national, state, civil society pressures, development interventions often fail to deliver intended outcomes and can exacerbate existing challenges (Hammett et al., 2014; italics ours). There is a widespread, implicit assumption, therefore, that development agendas are unproblematic and politically uncontested, and take the needs of 'development beneficiaries' fully into account. Applied social sciences in the field of development have also historically resided outside academia where clients expect concrete policy recommendations to respond to a priori goals and intentions (Ervin, 2005), which is at odds with both an ethnographic approach and participatory action research. In one sense, the space for agenda-setting is somewhat constricted and can leave gender professionals with minimal room to manoeuvre. However, in another sense, one can rely on and be creatively opportunistic by tapping the underlying ethos of development research, which is to generally effect equitable and sustainable outcomes, a normative engagement that is not always present in 'blue-sky' academic research undertakings.

\section{Politicised intersectionality}

Our final area of discussion focused on the incorporation of recent feminist theorising into the applied anthropology context of Carol's work with CIFOR. Given the centrality accorded to social difference in Carol's work, what kind of learning has there been in bringing academic conceptual frameworks into everyday practice? Intersectionality is a key concept that has considerable currency in academic feminist work. It originates as an activist concept, coming from the US black civil rights movement (Crenshaw, 1991). As a way of identifying and acting upon themes of power and marginalisation, it has since been incorporated into academic work as a concept for identifying the coproduction of inequalities through gender, race, class, age and so on (Mollett and Faria, 2013; Nightingale, 
2011), with some arguments suggesting it has lost its radical theorisation of white privilege and power on the way. Debates continue, even as the concept is being incorporated in order to add nuance to the gender frameworks used within environment and development organisations, including CIFOR. What has this meant in the context of Carol's work?

Carol: I re-read some stuff I wrote in 1977 after I finished writing an intersectionality manual recently. And I thought, 'God, is there really nothing new? I already wrote about that.' But looking at intersectionality - that's another thing that's difficult to translate into numbers because there's so many different categories. If you're a numbers freak, then you're not going to like intersectionality very well [laughter].

Becky: Too many variables floating around [laughter].

Babette: Talking about intersectionality, it is something that people nowadays read about a lot. And I agree with you that I think it's been around for quite some time, but we just didn't label it as intersectionality. I'm also hearing some feedback that maybe it's better to just use the term intersectionality rather than gender. What do you think about that? Or it's a way of looking at other forms of social differences and power, but at the same time de-centering gender. What do you feel about that?

Carol: Bimbika Sijapati Basnett and I began working with a colleague on the intersectionality manual I just mentioned, a couple of years ago (now published as Colfer et al., 2018). He was young, very smart, just out of graduate school, and he knew a lot about intersectionality. He argued against our approach of beginning with gender. He felt that gender should be presented as just one of the intersectional elements of identity in need of attention. Bimbika and I both felt that gender is something that is in every culture. It transcends everything else, is in all of the identities and none of the other identities is as ubiquitous as gender. We were also working within a program that focused on gender, so that was another more practical consideration. We won the argument but I don't know if we ever convinced him that this was the best way to go or not [laughter].

Becky: In the 'revisiting gender' project, Babette, do you remember, we did have this long conversation and decided that there's always an ethical question about if you don't mention gender it will just vanish completely? It will. It always has. And we need to be bold in making that statement, really.

Babette: Right. If development professionals can do away with it, they will.

Carol: I think many of us have had this struggle. And you can kind of throw some statistics around as well, which I think the UN does, on some of the gender inequities that are still incredibly persistent. Gender problems have not been solved. They keep resurfacing.

I think we would probably be able to reduce some of the antagonism about gender if we did a better job of looking at men in the same way that we're looking at women in gender research. I really feel it's time to do that, and began reading about it a few years back - there is some masculinity literature 
[as cited in Colfer 2020]. But some of it is so negative about men - it's even written by men, but it's pointing out problems that men create and also suffer. I don't think we've done a very good job of looking at men in the same sympathetic way we look at women analytically. The masculinity issue, particularly, and also in the ways that we've contrasted different femininities.

Becky: Yes, I think that goes missing when there are gender focal points in organisations, and that's often translated as the one who fixes women or sorts out women questions, rather than gender. It could be about masculinities within an organisation as well.

Carol: And masculinities are very, very powerful forces. I really think we need to pay more attention to them. I was thinking about it when I was doing some research in the US in 2017. This was a community where I did three years of ethnographic research in the 1970s; one dominant ideal masculinity for men there was to be a logger. To be strong, to be outdoors, to be in charge, to be bossy to one's wife, to run the household. There was this sort of ideal masculinity that a lot of men couldn't possibly fulfil. And also, when I was young, I remember men were supposed to be the ones who had to support the family; that was their job and they had to do it. Women have now been able to find jobs so that's the other side of the coin. We haven't paid attention to that and we should.

Becky: I'm sure that's right. The burden of being the breadwinner.

Carol: When I became a solid feminist in the 70s, I really saw it as a way of opening up avenues for women, but also reducing the pressures on men in this 'breadwinner' role, which was so clear in those days. It's become much less clear now. But there was a lot of pressure on men, and I thought that everybody would benefit. I still do, actually [laughter].

But I think maybe the entry point for this is the growing concern on the youth, isn't it? So applying intersectionality, right? There is now interest in young people in forestry, where masculinities do come in because some of their concerns are about the unemployment of male youth, and what that does in terms of self-esteem and related issues. In my recent US-based work (Colfer, 2018), I've also become sensitised to the differences in American masculinity as people age. It's not entirely clear if the differences I saw in 2017, vis à vis, 1975, were societal differences, agerelated differences, or even just differences in my own perceptions! But they were extreme.

Gendered experiences are crucial and fundamental to understanding all things social, as gender is in some way refracted in all social phenomena as is evidenced through the ethnographies produced by Carol, amongst others at CIFOR. Intersectionality has been used not only as an analytical tool, but also as a heuristic to amplify and highlight specific problems that are generally overlooked and silenced (Hancock, 2016). The growing recognition of the importance of intersectionality and its application to new contexts that lie beyond its social justice origins have led to suggestions that its critical edge and transformative potential are being blunted. 
This seeming 'depoliticisation' happens when intersectionality is used merely as a descriptive tool without paying attention to its original formulation as an analysis of power dynamics (Mügge et al., 2018; Mollett \& Faria, 2013).

Carol: I was thinking that one difference between earlier attentions to intersectional issues and current ones called 'intersectionality' revolved around being less explicit earlier about the power element. Although I did deal with power in my own earlier analyses, I didn't have a concept like intersectionality per se that required it, where power was integral to the concept.

The work that has been undertaken by Carol and her team at CIFOR to think through applications of intersectionality in their gender programming has brought internal debates about what this means for 'gender', particularly where efforts to bring 'gender analysis' into institutional practice can feel fragile and temporary. A strategic decision was made in writing the 'manual' to continue to foreground 'gender' but to challenge binary thinking by looking at how gender is produced and experienced through other axes of power and marginalisation (Colfer et al., 2018). There are resonances with Carol's earlier work, but as she notes, the question of 'power' was not necessarily foregrounded even as an ethnographic approach to community-based research in forest contexts begins from a position of complicating simple categories such as 'gender'.

\section{Conclusion}

We began this chapter by reflecting on the power of doing ethnography in gender and natural resource management research contexts, and its capacity to understand the plurality of knowledges and with that, bridge diverse groups' understandings of society in interaction with the natural world. In doing our ethnographies, we also encounter uneasy issues of representation of our research subjects, as well as accusations that we are disrupting cultures as we interrogate power relations.

The often-repeated charge of disrupting cultures through gender work is often used misogynistically to undervalue the work itself in order to avoid uncovering or unsettling hierarchical social relations that serve to disadvantage women and other social groups (by caste, class, age or ethnicity). This accusation often ignores real life experiences of women and other groups who may suffer forms of marginalisation. At the same time this ignores the fact that 'culture' is dynamic and changing. Ethnography can be a way of opening up intractable areas of unequal gender relations and can thoughtfully challenge notions that 'culture' and cultural norms represent a 'no-go area' or a dead-end, ideas that disrupt emancipatory processes towards gender equality, rather than advancing it. Bringing social movement concepts such as intersectionality into applied contexts via academia is not always a smooth process, it complicates an emphasis on 'gender', prompting debate as to whether gender should be pre-assumed to be a key axis of power or whether that assumption should be converted into an empirical question: under what circumstances is 'gender' the principal axis of power? 
Carol's extensive experience as an anthropologist working in interdisciplinary settings around the world, and the reflexivity that accompanies an ethnographic approach have demonstrated the importance of seeing the world from multiple perspectives: not only from those of the local communities with which she works, but also those of government bureaucrats and her fellow scientists. The advantage of her ethnographic approach comes through its principal mode of data collection: community-based fieldwork. Working in field-based contexts brings to life the gender analyses that might otherwise be unconvincing for some. Her work has involved some multi-directional navigation across the boundary between academic and applied anthropology in her work as a gender professional. Bringing an (academic) intersectional analysis of gendered power into that reflexivity complements her observation that the best laid plans for inclusive community engagement in projects seeking to improve well-being and participation can be derailed by sticky gender norms that can also challenge the agency of the feminist ethnographer in making a difference.

\section{References}

Bebbington, A., Guggenheim, S., Olson, E., \& Woolcock, M. (2004). Exploring social capital debates at the World Bank. Journal of Development Studies, 40(5), 33-64.

Chambers, R. (1994). The origins and practice of participatory rural appraisal. World Development, 22(7), 953-969.

Colfer, C. J. P. (1983). On communication among 'unequals'. International Journal of Intercultural Communication, 7, 263-283. Reprinted in C. J. P. Colfer, M. Elias, B. Sijpati Basnett, \& S. S. Hummel (Eds.), Earthscan Reader on Gender and Forests, London and New York: Routledge, 2017.

Colfer, C. J. P. (2005a). The Complex Forest: Communities, Uncertainty, and Adaptive Collaborative Management. Washington DC: Resources for the Future.

Colfer, C. J. P. (Ed.) (2005b). The Equitable Forest: Diversity, Community and Resource Management. Washington, DC: RFF/CIFOR.

Colfer, C. J. P. (2018). 'Before and after the 'Timber Wars': Context, change and potential collaboration on the Olympic Peninsula. Humboldt Journal of Social Relations, 40, 137-162.

Colfer, C. J. P. (2020). Masculinities in Forests: Representations of Diversity. The Earthscan Forest Library. London: Routledge.

Colfer, C.J., Sijapati Basnett, B., \& Ihalainen, M. (2018). Making sense of 'intersectionality': A manual for lovers of people and forests. CIFOR Occasional Paper, 184, 40.

Colfer, C. J. P., Andriamampandry, E., Asaha, S., Lyimo, E., Martini, E., Pfund, J. L., \& Watts. J. (2011). Participatory action research for catalyzing adaptive management: Analysis of a 'fits and starts' process. Journal of Environmental Science and Engineering, 5 (1), 28-43.

Colfer, C. J. P. with Prabhu, R., Gunter, M., McDougall, C., Miyasaka Porro, N., \& Porro, R. (1999a). Who Counts Most? Assessing Human Well-Being in Sustainable Forest Management. Edited by Ravi Prabhu. 9 vols. Vol. 8, C\&I Toolbox. Bogor, Indonesia: CIFOR.

Colfer, C. J. P., and others. (1999b). The BAG (Basic Assessment Guide for Human WellBeing). Edited by Ravi Prabhu. Vol. 5, C\&I Toolbox. Bogor, Indonesia: CIFOR. 
Colfer, C. J. P. , Brocklesby, M., Diaw, C., Etuge, P., Gunter, M., Harwell, E|., McDougall, C., Porro, N.M., Porro, R., Prabhu, R., Salim, A., Sardjono, M.A., Tchikangwa, B., Tiani, A.M., Wadley, R.L., Woefel, J., \& Wollenberg, E. (1999c). The Grab Bag: Supplementary Methods for Assessing Human Well-Being. Edited by Ravi Prabhu. Vol. 6, C\&I Toolbox. Bogor, Indonesia: CIFOR.

Colfer, C. J. P., Wadley, R. L. \& Widjanarti, E. (1996). Using indigenous organizations from West Kalimantan. In D. M. Warren, P. Blunt \& D. Marsden (Eds.), Indigenous Organisations and Development, (pp. 228-238). London: Kegan Paul International.

Craven, C., \& Davis. (2013). Feminist activist ethnography. In C. Craven (Ed.), Feminist Activist Ethnography: Counterpoints to Neoliberalism in North America (pp. 1-20). Lanham, Maryland: Lexington Books.

Crenshaw, K. (1991). Mapping the margins: Intersectionality, identity politics, and violence against women of color. Stanford Law Review, 43(6), 1241-1299.

Crewe, E., \& Axelby, R. (Eds.) (2013). Anthropology and Development: Culture, Morality and Politics in a Globalised World. Cambridge: Cambridge University Press.

Dove, M.R., \& Kammen, D. M. (2015). Science, Society and the Environment: Applying Anthropology and Physics to Sustainability. London: Routledge.

Elmhirst, R., Siscawati, M., \& Colfer, C. J. P. (2016). Revisiting gender and forestry in Long Segar, East Kalimantan: Oil palm and divided aspirations. In C. J. P. Colfer, B. Sijapati Basnett, \& M. Elias (Eds.), Gender and Forestry: Climate Change, Tenure, Value Chains, and Emerging Issues (pp. 300-317). London: Earthscan/CIFOR.

Ervin, A. M. (2005). Applied Anthropology: Tools and Perspectives for Contemporary Practice. Boston, MA: Pearson Education, Inc.

Eversole, R. (2018). Anthropology for Development: From Theory to Practice. London: Routledge.

Forsyth, T. (2011). Expertise needs transparency not blind trust: A deliberative approach to integrating science and social participation. Critical Policy Studies, 5(3), 317-322.

Gardner, K., \& Lewis, D. (2015). Anthropology and Development: Challenges for the Twenty-first Century. London: Pluto Press.

Hancock, A. M. (2016). Intersectionality: An Intellectual History. Oxford: Oxford University Press.

Harding, S. (1987). Introduction: Is there a feminist method? In S. Harding (Ed.), Feminism and Methodology (pp. 1-14). Indiana University Press.

Hammett, D., Twyman, C., \& Graham, M. (2014). Research and Fieldwork in Development. London: Routledge.

Hesse-Biber, S. (2014). Feminist research: Exploring, interrogating, and transforming the interconnections of epistemology, methodology, and method. In Handbook of Feminist Research: Theory and Praxis (pp. 2-26). Thousand Oaks CA: SAGE Publications.

Komarudin, H, Siagian, Y. L, Colfer, C.J.P. with Neldysavrino, Yentirizal, Syamsuddin \& Irawan, D. (2011). The role of collective action in securing property rights for the poor: A case study in Jambi Province, Indonesia. In E. Mwangi,, H. Markelova \& R. Meinzen-Dick (Eds.). Collective Action and Property Rights for Poverty Reduction: Insights from Africa and Asia (pp. 235-269). Philadelphia: University of Pennsylvania Press.

Kunz, R., \& Prügl, E. (2019). Introduction: Gender experts and gender expertise. European Journal of Politics and Gender, 2(1), 3-21. https://doi.org/10.1332/251510819X1 5471289106077

Lamphere, L. (2004). The convergence of applied, practicing, and public anthropology in the 21st century. Human Organization, 431-443. 
Li, T. M. (2011). Rendering society technical: Government through community and the ethnographic turn at the World Bank in Indonesia. In D. Mosse (Ed.) Adventures in Aidland: The Anthropology of Professionals in International Development (pp. 57-80). Oxford: Berghahn.

Mollett, S., \& Faria, C. (2013). Messing with gender in feminist political ecology. Geoforum, 45, 116-125.

Mügge, L., Montoya, C., Emejulu, A., \& Weldon, S. L. (2018). Intersectionality and the politics of knowledge production. European Journal of Politics and Gender, 1(1-2), $17-36$.

Mutimukuru-Maravanyika, T., Prabhu, R., Matose, F., Nyirenda, R. and Kozanayi, W. (2008). Facilitating adaptive collaborative management in forested landscapes: The Mafungautsi Case Study. In A. Mandondo, R. Prabhu and F. Matose (Eds.), Coping Amidst Chaos: Studies of Adaptive Collaborative Management from Zimbabwe (pp. 15-64). Bogor, Indonesia: Center for International Forestry Research.

Nagar, R. (2003). Collaboration across borders: moving beyond positionality. Singapore Journal of Tropical Geography, 24(3), 356-372.

Nightingale, A. J. (2011). Bounding difference: Intersectionality and the material production of gender, caste, class and environment in Nepal. Geoforum, 42(2), 153-162.

Reinharz, S. (1992). Feminist Methods in Social Research. Oxford University Press.

Stacey, J. (1988). Can there be a feminist ethnography? Women's Studies International Forum, 11(1), 21-27. https://doi.org/10.1016/0277-5395(88)90004-0

Standa-Gunda, W., Mutimukuru, T., Nyirenda, R., Haggith, M., \& Vanclay, J. (2003). Participatory modelling to enhance social learning, collective action and mobilization among users of the Mafungautsi Forest, Zimbabwe. Small-Scale Forest Economics, Management and Policy, 2(2), 313-326.

Vanclay, J., Prabhu, R., \& Sinclair, F. (2006). Realizing Community Futures: A Practical Guide to Harnessing Natural Resources. London: Earthscan

Wolf, D. L. (1996). Feminist Dilemmas In Fieldwork. New York: Routledge. Retrieved from https://www.taylorfrancis.com/books/e/9780429962394

Ybema, S., Yanow, D., Wels, H., \& Kamsteeg, F. (2009). Organizational Ethnography: Studying the Complexities of Everyday Life. London: Sage. https://doi. org/10.4135/9781446278925 